\title{
Comparison of Somatotype Characteristics and Anthropometric Proportional Relations of Elite Wrestlers Between Styles and Weights
}

\author{
Defne Öcal Kaplan ${ }^{1}$, İbrahim Yıldıran ${ }^{2}$ \\ ${ }^{1}$ Kastamonu University School of Physical Education and Sports, Kastamonu, Turkey \\ ${ }^{2}$ Gazi University School of Physical Education and Sports, Ankara, Turkey \\ Correspondence: Defne Öcal Kaplan, Kastamonu University School of Physical Education and Sports, Kastamonu, \\ Turkey.
}

Received: March 25, 2018

doi:10.11114/jets.v6i6.3103

\author{
Accepted: May 10, $2018 \quad$ Online Published: May 25, 2018
}

URL: https://doi.org/10.11114/jets.v6i6.3103

\begin{abstract}
In this paper, comparison of somatotype characteristics and anthropometric proportional relations of elite wrestlers at the level of styles and weights and, contribution to improvement and orientation of sport is aimed. 57 elite wrestlers took place in the European Championship Preparatory Camp of Turkish National Adults Wrestling Team (31 greco-roman style with 7 light weight, 14 medium weight and 10 heavy weight -with av. height: $168.9 \mathrm{~cm}$. and av. weight: $81.1 \mathrm{~kg}$.; 26 free style with 8 light weight, 12 are medium weight and 6 heavy weight -with av. height: 173.0 $\mathrm{cm}$. and av. weight: $87.9 \mathrm{~kg}$ ), analyzed in this study. As a result of anthropometric measurements, there are no meaningful differences between free style and greco-roman elite wrestlers both in style and weigh. Wrestlers, as evaluated in somatotype, free and greco-roman styles are characterized as endomorphic mesomorphy, lightweight wrestlers are measured as balanced mesomorphy, medium-weight wrestlers are found endomorphic mesomorphy and heavy-weight wrestlers are characterized as endomorphic mesomorphy. Meaningful difference have found between weights. In spite of there is no differentiate effect of styles for wrestlers, partake in the similar training, nutrition and competition programs from childhood, weight, leaning on differentiates of somatotypes in the frame of the components like height, weight, length of bust and arm etc., emanates differences.
\end{abstract}

Keywords: greco-roman style wrestling, free style wrestling, anthropometry, somatotype

\section{Introduction}

Wrestling is widely recognized as the oldest competitive sport and it has featured in every Olympic Games since its ancient conception. There are two different forms of men's wrestling at the modern Olympics: freestyle and Greco-Roman. Greco-Roman wrestlers must not use the legs to trip or lift an opponent, or attack an opponent's legs, while in freestyle competition wrestlers can use their legs and may hold opponents above or below the waist.

Wrestling have arisen from physical strength and composition of techniques which are the ways of using that force in the most efficient manner; and is a contest for achieving superiority between two humans on the wrestling mat with the specified dimensions without using any equipments and in accordance with the specified rules. For the wrestling sport basically composed of strength, endurance, technique and intelligence; the essential conditions for success are skill and body composition as well as the factors such as desire to win, experience, deciding quickly and getting use of scientific training programs. Body build and composition in wrestlers depend on their weight category.

Managing modern wrestling by rules resulted in two different styles: Free and Greco-roman. For wrestlers, determining in which style and in which weight the wrestlers shall get involved in the contest in the light of body compositions must be performed on the results of anthropometric measurements. The best wrestlers, categorized as elite athletes, are similar in terms of body build and constitute a group which is less differentiated than wrestlers who obtain worse results. Body composition is an important factor for elite-sport performance and moreover, this competition system, based on weight categories, determines morphological differentiation of wrestlers (Jagiełło and Kruszewski, 2009). Anthropometric criteria which comprise primary dimension of physical data are used for arranging training programs and determining contest strategies of the wrestlers. With the training programs applied in wrestling sport it is provided for wrestlers to achieve their upper levels of physiological capacities and to improve their physical skills (Charzewski, Głaz \& Kuźmicki, 1991). 
Anthropometry is a method concerning with measuring body dimensions and introducing rational statements (Heyward \& Wagner, 2004). On the other hand somatotype is displaying body types of human, and determining body type and composition regardless of dimensions. As well as being an important method in sports, anthropometry, in particular, is important in talent selection phase with the principle "sport according to body type" for upper level success. "Heath and Carter Somatotype Determination Method" has advantages such as making calculations more objectively, determining somatotypes quicker and minimizing individual differences in evaluation phase. At the end of the calculations according to their somatotype differences results are listed in three different titles: endomorph, mezomorph and ectomorph (Eston \& Reilly, 1996).

In theory, elite sportsmen/sportswomen are expected to have the most appropriate physical structure for their sport branches. General hypothesis about this subject is that the sportsman/sportswoman is not able to achieve high level success without the required physical properties. Growing children show differences in somatotype. By that reason somatotype development differences are considered especially in skill selection phase and similarly those two concepts are correlated by taking into consideration that growing patterns may change in some sport branches. All those data show the effects of training on growing and maturation (Fox, Bowers \& Foss, 1988). As a result of the studies performed it was determined that wrestlers are in different somatotype categories in terms of their weights. Making a general evaluation, light weight wrestlers tend to be balanced mezomorph and heavy weight wrestlers tend to be endomezomorph (Zorba, 2005).

The aim of present study is to make contributions for improving and orienting sportsmen/sportswomen who wish to perform wrestling in a professional manner by detecting the somatotype properties and anthropometric rational relations of elite wrestlers at the level of styles and weights.

\section{Method}

\subsection{Research Group}

The research group is consisted of totally 57 elite free style ( 8 of light weight, 12 of middle weight and 6 of heavy weight) and Greco-roman style (7 of light weight, 14 of middle weight and 10 of heavy weight) wrestlers who take place in Turkish Wrestling Adult National Team and who attended Preparatory Camp for European Championship.

\subsection{Data Collection Methods}

Data Concerning Demographic Variables: Aiming to determine personal and basic information concerning wrestling sport of elite wrestlers; date of birth, educational status, wrestling style and weight, sports age, weekly training time had been asked. In addition to determine how the wrestlers are elite they were asked about how many times they had attended national and international contests and their best results in these contests were recorded.

Data Concerning Anthropometric Measurements: For determination of somatotypes and anthropometric profiles of the wrestlers Holtain brand anthropometry for height, electronic scale sensitive for $100 \mathrm{~g}$ for body weight, Harpanden brand skinfold for skinfold thicknesses (triceps, subscapular, supraspinale and calf), calipers for bone breadth (humerus epicondular breadth and femur epicondular breadth) and tape measure for peripheral measurements (upper arm and calf) were used (Weiner \& Lourie, 1981;Lohman, Roche \& Martorell, 1988). Somatotypes of the individuals were determined reliably in accordance with the international standards with the measurements made and specified regression formulas and were also displayed on somatocards. In order to calculating body fat percentage, formula developed by Sloan and Weir for males was used (Heyward \& Wagner, 2004).

Body density $(\mathrm{gm} / \mathrm{ml})=1.1043-(0.00133 \times$ Femur Skinfold $)-(0.00131 \times$ Subscapular Skinfold $)$

Body Fat Percentage $(\%)=(4.57 /$ density -4.142$) \times 100$

In order to show the anthropometric rational relations of elite wrestlers bitrochanteric diameter, biacrominal diameter, bust length, lower body length, tibia length, arm length, forearm length, neck circumference, waist circumference were measured in accordance with the international standards (Lohman, Roche \& Martorell, 1988) and their rational relations were analyzed.

\subsection{Methods for Data Evaluation}

Findings observed from the measurements made showed anthropometric ratios and somatotypes of the research group by basic statistical calculations. Formulas used to determine somatotypes from regression equation (Carter \& Healt, 1990) are as follows:

$$
\text { 1. Endomorph }=-0.7182+0.1451(\mathrm{X})-0.00068\left(\mathrm{X}^{2}\right)+0.0000014\left(\mathrm{X}^{3}\right)
$$

$\mathrm{X}=$ (sum of triceps, subscapular and supraspinale skinfolds)

For correction according to length, the coefficient 170.18/length is multiplied by total skinfold thickness. 
2. Mezomorph $=[(0.858 \times$ elbow breadth $)+(0.601 \times$ knee breath $)+(0.188 \times$ corrected forearm circumference $)$ $+(0.161 \times$ corrected calf circumference $)]-($ length $\times 0.131)+4.50$

3. Ectomorph $=$ LWR $\times 0.732-28.58$

Length Weight Ratio $($ LWR $)=$ Length $/ \sqrt[3]{\text { Weight }}$

In case that the ponderal index is less than 40.75 and greater than 38.25 then the formula below is used:

(LWR $x$ 0.463)-17.63. If ponderal index is less than or equal to 38.25 then 0.1 is added to the resulting value (Carter \& Health, 1930).

(LWR x 0.463)-17.63+0.1

While classifying the elite wrestlers in the sampling group according to their weights $55-60 \mathrm{~kg}$ for light weight, 66-74-84 kg for middle weight and 96-120-+120 kg for heavy weight had been taken as base.

\subsection{Statistical Analysis}

After recording the information on data forms to SPSS 12.0 program statistical calculations have been performed, findings observed from the study were analyzed and evaluated.

It is assumed that the frequency, cross tabulation of the findings observed from the study are at the significance level of $\mathrm{p}<0.005$, by performing t-test and bilateral ANOVA statistics (Green, Salkind \& Akey, 2000) a research design have been constructed in a manner that alternative hypothesis are accepted.

\section{Results}

Measurements showed that the subjects have an average length of $171.19 \pm 8.7 \mathrm{~cm}$ and an average body weight of $84.8 \pm 18.9 \mathrm{~kg}$. In the result of anthropometric measurements of the wrestlers it was determined that average arm length which has an important role in wrestler physiology is $75.2 \mathrm{~cm}$, average forearm length is $26.2 \mathrm{~cm}$, average lower body length is $102.0 \mathrm{~cm}$, average chest circumference is $104.8 \mathrm{~cm}$ and average waist circumference is $83.4 \mathrm{~cm}$.

Results of skinfold thickness measurements do not show a significant difference between skinfold thicknesses and body fat percentages of wrestlers and wrestling styles.

Table 1. Research group of anthropometric measurement results comparision between styles and weights

\begin{tabular}{|c|c|c|c|c|c|}
\hline & \multirow[b]{2}{*}{$\mathbf{M} \pm \mathbf{S D}$} & \multicolumn{2}{|c|}{ STYLE } & \multicolumn{2}{|c|}{ WEIGHT } \\
\hline & & $\mathbf{F}$ & Sig-2-tailed & $\mathbf{F}$ & Sig-2-tailed \\
\hline Height $(\mathrm{cm})$ & $171.19 \pm 8.73$ & 3.44 & 0.069 & 42.40 & $0.000^{*}$ \\
\hline Weight $(\mathrm{kg})$ & $84.86 \pm 18.95$ & 2.57 & 0.115 & 117.83 & $0.000^{*}$ \\
\hline Humerus biepicondylus breadth $(\mathrm{cm})$ & $7.13 \pm 0.53$ & 1.74 & 0.193 & 27.21 & $0.000 *$ \\
\hline Femur biepicondylus breadth (cm) & $9.93 \pm 0.70$ & 0.7 & 0.405 & 33.39 & $0.000^{*}$ \\
\hline Arm girth flexed (tensed) $(\mathrm{cm})$ & $37.19 \pm 3.40$ & 0.88 & 0.350 & 51.86 & $0.000 *$ \\
\hline Calf circumference $(\mathrm{cm})$ & $37.39 \pm 3.55$ & 0.06 & 0.807 & 57.10 & $0.000 *$ \\
\hline Sitting height $(\mathrm{cm})$ & $92.19 \pm 4.24$ & 1.14 & 0.289 & 34.73 & $0.000 *$ \\
\hline Ower extremity length $(\mathrm{cm})$ & $102.10 \pm 6.98$ & 1.21 & 0.276 & 31.12 & $0.000 *$ \\
\hline Bitrochanteric breadth $(\mathrm{cm})$ & $33.78 \pm 2.85$ & 0.03 & 0.860 & 20.98 & $0.000^{*}$ \\
\hline Biacrominal breadth $(\mathrm{cm})$ & $43.66 \pm 3.64$ & 5.48 & 0.023 & 51.42 & $0.000^{*}$ \\
\hline Arm bength $(\mathrm{cm})$ & $75.21 \pm 4.44$ & 0.25 & 0.619 & 21.44 & $0.000^{*}$ \\
\hline Elbow- wrist length $(\mathrm{cm})$ & $26.27 \pm 1.76$ & 0.13 & 0.720 & 13.38 & $0.000^{*}$ \\
\hline Minimal neck circumference $(\mathrm{cm})$ & $41.58 \pm 2.81$ & 0.52 & 0.474 & 28.63 & $0.000 *$ \\
\hline Chest circumference $(\mathrm{cm})$ & $104.86 \pm 10.74$ & 1.98 & 0.165 & 37.94 & $0.000 *$ \\
\hline Waist circumference $(\mathrm{cm})$ & $83.50 \pm 10.50$ & 0.11 & 0.733 & 72.45 & $0.000^{*}$ \\
\hline
\end{tabular}

$* \mathrm{p}<0.005$

Findings represented and statistical measurements performed to test the hypothesis developed in the scope of this research aimed to show if the results of anthropometric measurements of elite wrestlers display difference between styles and weights. Results of variance analysis concerning anthropometric measurements performed are presented in table 1. 
Table 2. Research group of comparision on between the styles and weigths skinfold measurement results

\begin{tabular}{|c|c|c|c|c|c|}
\hline & \multirow[b]{2}{*}{$\mathbf{M} \pm \mathbf{S D}$} & \multicolumn{2}{|c|}{ STYLE } & \multicolumn{2}{|c|}{ WEIGHT } \\
\hline & & $\mathbf{F}$ & Sig-2-tailed & $\mathbf{F}$ & Sig-2-tailed \\
\hline Triceps skinfold (mm) & $8.34 \pm 3.2$ & 0.25 & 0.616 & 13.14 & $0.000^{*}$ \\
\hline Subscapular skinfold (mm) & $12.28 \pm 4.6$ & 4.03 & 0.050 & 31.64 & $0.000^{*}$ \\
\hline Subraspinale skinfold (mm) & $9.01 \pm 5.2$ & 8.37 & 0.006 & 26.09 & $0.000^{*}$ \\
\hline Suprailiac skinfold (mm) & $11.41 \pm 7.2$ & 0.18 & 0.668 & 36.85 & $0.000^{*}$ \\
\hline Medial calf skinfold (mm) & $7.90 \pm 4.2$ & 2.13 & 0.150 & 22.42 & $0.000^{*}$ \\
\hline Abdominal skinfold (mm) & $13.22 \pm 7.6$ & 0.45 & 0.502 & 49.60 & $0.000^{*}$ \\
\hline Biceps skinfold (mm) & $3.99 \pm 0.9$ & 5.53 & 0.023 & 10.95 & $0.000^{*}$ \\
\hline Midthigh skinfold (mm) & $10.23 \pm 3.6$ & 3.54 & 0.065 & 14.98 & $0.000^{*}$ \\
\hline
\end{tabular}

Results of statistical tests concerning the skinfold differences of wrestlers between styles and weights are given in Table 2.

By the analysis performed it is observed that body fat percentages of wrestlers differ between weights but not between styles. The average body fat percentages of free style wrestlers is $9.85 \%$ (minimum $6.40 \%$, maximum 18.40\%) while the average body fat percentages of Greco-roman style wrestlers is $12.13 \%$ (minimum $6.7 \%$ maximum 21.9\%).

Table 3. Odds comparison of anthropometric research group

\begin{tabular}{lcccccc}
\hline & \multicolumn{2}{c}{ STYLE } & & \multicolumn{3}{c}{ WEIGHT } \\
\cline { 2 - 3 } & Free & $\begin{array}{c}\text { Greco- } \\
\text { Roman }\end{array}$ & & $\begin{array}{c}\text { Light } \\
\text { Weight }\end{array}$ & $\begin{array}{c}\text { Middle } \\
\text { Weight }\end{array}$ & $\begin{array}{c}\text { Heavy } \\
\text { Weight }\end{array}$ \\
\hline Sitting height/stature & 0.5409 & 0.5370 & & 0.5432 & 0.5378 & 0.5361 \\
Arm length/stature & 0.4416 & 0.4462 & & 0.4405 & 0.4482 & 0.4408 \\
Over extremity length/stature & 0.5960 & 0.5959 & & 0.5902 & 0.5926 & 0.6068 \\
Sitting height/over extremity length & 0.9080 & 0.9022 & & 0.9213 & 0.8842 & 0.9080 \\
Elbow-wrist length/arm length & 0.3496 & 0.3590 & & 0.3529 & 0.3579 & 0.3514 \\
Bitrochanteric breadth/biacromial breadth & 0.7879 & 0.7645 & & 0.7805 & 0.7827 & 0.7579 \\
Waist circumference/chest circumference & 0.8044 & 10.184 & & 0.7872 & 0.7751 & 12.827 \\
Medial calf skinfold/triceps skinfold & 0.8756 & 0.9847 & & 0.8573 & 0.8481 & 11.490 \\
\hline
\end{tabular}

With the measurements made it is observed that basic body ratios of the wrestlers do not show significant difference in terms of styles and weights. For example; the ratio between bust which has an important role in wrestling sport and length were observed to range between 0.52 and 0.56 for free style wrestlers while the values were between 0.51 and 0.57 for Greco-roman wrestlers. The same ratios become significant within ranges of 0.52-0.57, 0.52-0.56 and 0.51-0.56 for light weight, middle weight and heavy weight wrestlers, respectively.

9 of free style wrestlers revealed balanced mezomorph and 17 revealed endomorphic mezomorph while 8 of Greco-roman style wrestlers showed balanced mezomorph and 23 showed endomorphic mezomorph.

5 of free style light weight wrestlers were balanced mezomorph and 3 were endomorphic mezomorph while 5 of Greco-roman light weight wrestlers were in balanced mezomorph and 2 were endomorphic mezomorph somatotype.

4 of free style middle weight wrestlers were balanced mezomorph and 8 were endomorphic mezomorph while 3 of Greco-roman middle weight wrestlers were in balanced mezomorph and 11 were endomorphic mezomorph somatotype.

Heavy weight wrestlers of both free and Greco-roman styles all exhibited endomorphic mezomorph characteristics.

The wrestlers' somatotypes were calculated as 2.15-6.14-1.17 for light weight, 2.59-6.70-0.75 for middle weight and 4.12-7.90-0.18 for heavy weight. Endomorph, mezomorph and ectomorph components of styles according to weights are given in Figure 1, Figure 2 and Figure 3 in details. 


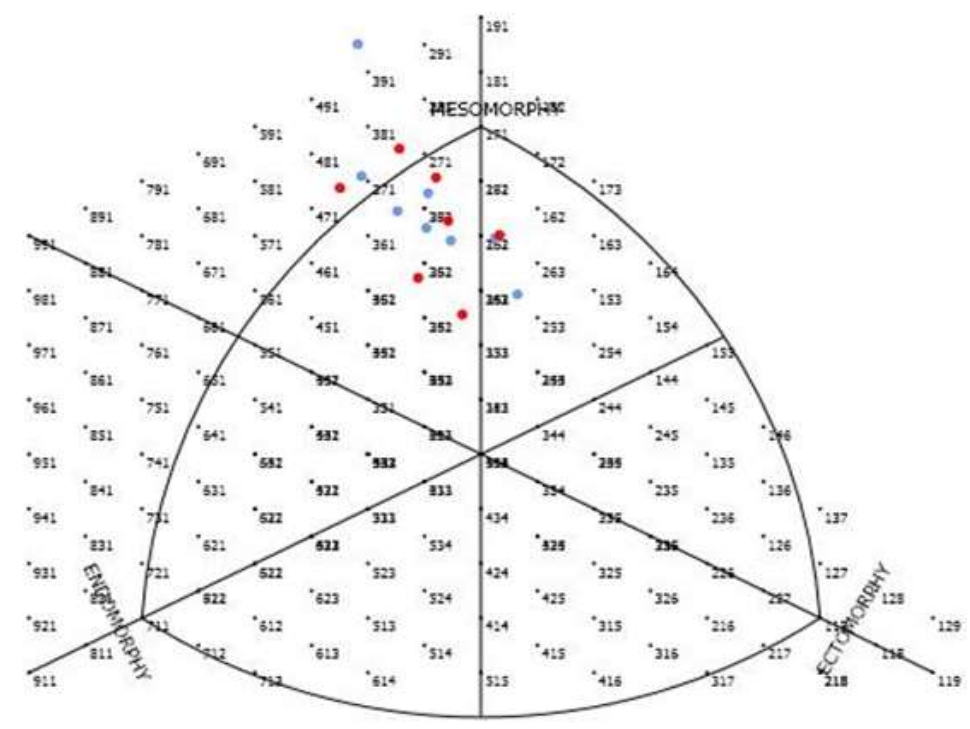

Figure1. Distribution of lightweight wrestlers' somatotype $(\mathrm{N}=15)$

$\because:$ Free Style $\quad$ :Greco-roman

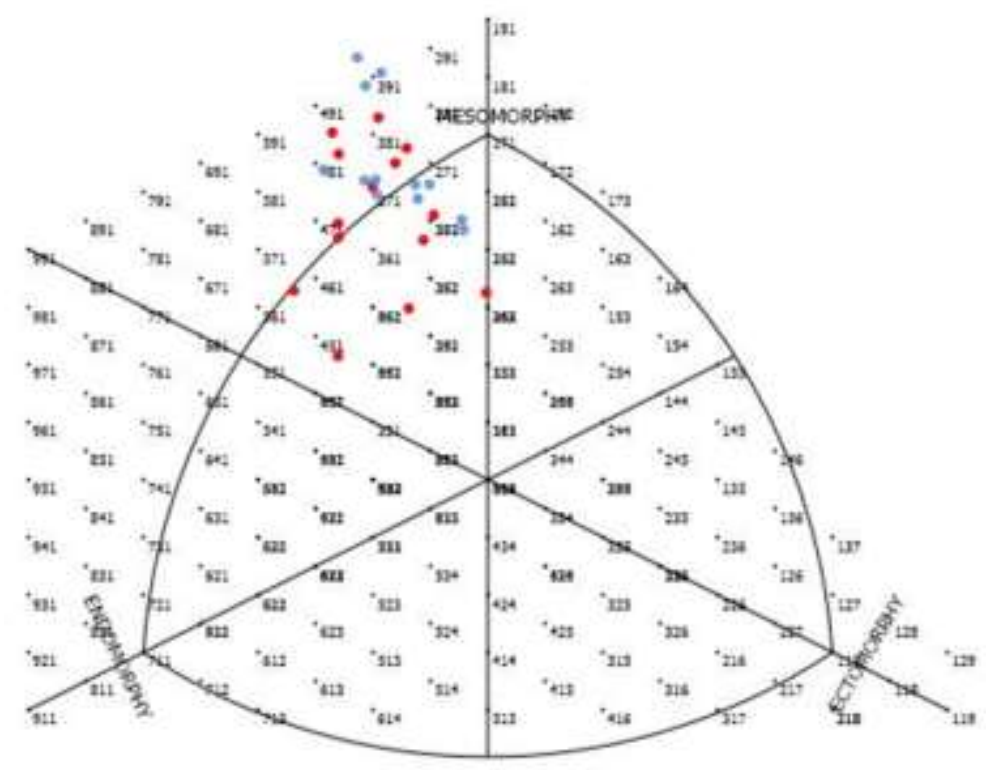

Figure 2. Distribution of Middleweight Wrestlers' somatotypes ( $\mathrm{N}=26)$ 


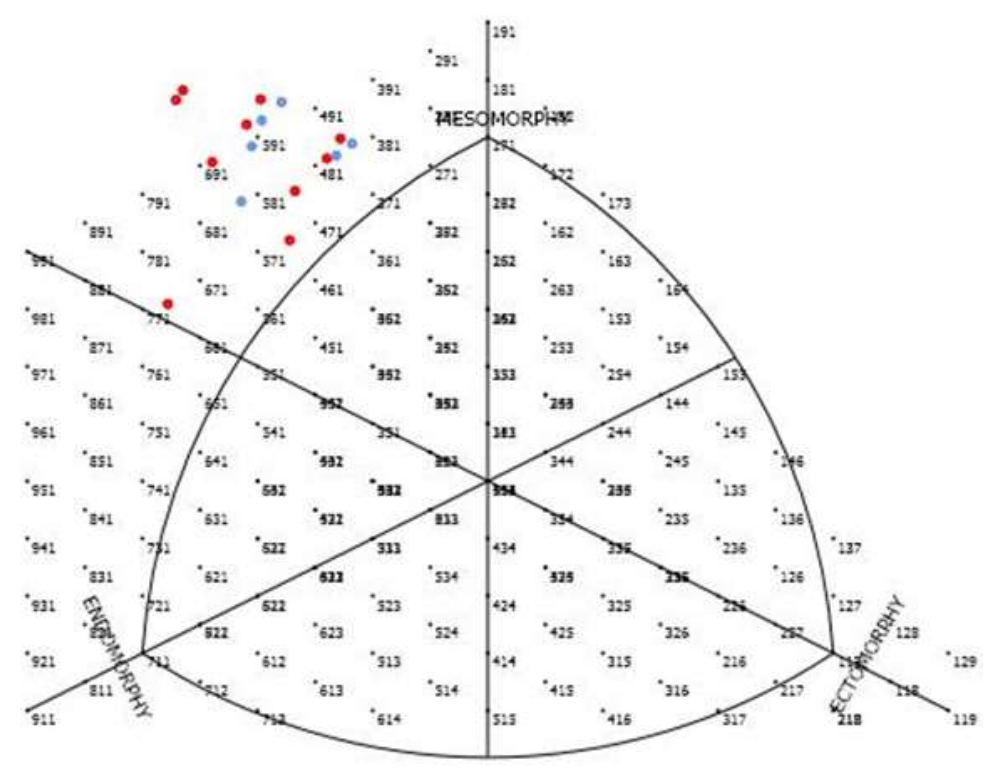

Figure 3. Distribution of heavyweight wrestlers' somatotypes. $(\mathrm{N}=16)$

\section{Discussion}

Diversity in sport branches result by changes in growing pattern of individuals especially who engage in as of small ages. Performing the sports activity at a professional level and moreover getting involved in the national and international contests at elite level are primarily become possible by using the body composition efficiently and effectively. In wrestling sport somatotype properties and anthropometric rational relations provide general information having a characteristic of clues about the prediction of sportive skills and by composing with other data provide a basis for sportive performance (Karl, 2001).

In order to complete body development and to achieve high performance it is needed to be within a specific age range. Average age of the wrestlers involved in the study was found to be 23.35 , and it is detected that they had completed their development in professional levels. Bompa had stated that the age for achieving high performance in wrestling sport is between 24 and 28 (Bompa \& Haff, 2009). Average age of wrestlers who had taken place in the Greco-Roman Style World Wrestling Championship was detected to be 25.8 years (Nilsson, Csergö, Gullstrand, Tveit \& Refsnes, 2002). By the study in which age depending samples of anthropometric characteristics of young wrestlers within the ages of 8 and 14 were examined, the subjects were separated into six groups according to their age ranges, and many anthropometric measurements were compared and at the end of the study only femur circumferences were found to be different (Camic et al., 2009).

Evaluating the lengths of the wrestlers involved in the study in terms of physical compatibility, it was detected that there was not a length difference between the styles but on the other hand there was a significant difference in length among the weights in favor of heavy weight wrestlers (at significance level of $\mathrm{p}=0.005, \mathrm{df}=2$ and $\mathrm{F}=44.078$ ). These results are similar to measurement results performed by Rajabi and colleagues on elite Greco-roman and free style wrestlers (free style wrestlers have an average length of $176 \pm 7 \mathrm{~cm}$ and Greco-roman wrestlers have an average length of $176 \pm 4 \mathrm{~cm}$ ) (Rajabi, Doherty, Goodarzi \& Hemayattalab, 2008).

Having the ideal "sport-specific" body build is only one part of a complex interaction that leads to optimal performance. The ideal balance to be observed for the wrestlers depends on the body fat percentage which may be carried without having a negative change on performance. When the data distribution in the study performed is examined it can be observed that there is a linear relationship between body weight and body fat. In the present study average body weight of free style wrestlers was $81.1 \mathrm{~kg}$, average body fat percentage was $9.85 \%$ and average body weight of Greco-roman style wrestlers was $87.9 \mathrm{~kg}$, average body fat percentage was $12.13 \%$. With these results no significant differences had been observed in term of statistical values while it had been detected that there is a direct proportion with body weights as comparing body fat percentages between weights. The reality that $17 \%$ of human body weight is composed of fat molecules (Guyton, \& Hall, 2001) discloses that body weight percentage difference between the weights. Kazemi, Waalen, Morgan and White (2006), in the study on determining profiles of 102 Olympic taekwondo contestants had found that the body fat index of players who are placed and whose average age is 24.4 years, average body weights is $73.4 \mathrm{~kg}$ and average length is $1.83 \mathrm{~m}$ is 21.9 . 
Obtaining optimal body composition is one of the major concerns of wrestlers, and percent body fat is considered to be especially important by athletes. Clark, Robert and Jude (2002), in the study on colleague wrestlers whose average age is 20.20 years had found that the body weights of the wrestlers is $74.44 \mathrm{~kg}$ and body fat percentages is $9.70 \%$.

Bujak, Gierczuk, Hubner-Wozniak and Saulite (2016) calculated the body fat percentages of the 28 elite greco-roman wrestlers as $10.1 \pm 4.05 \%$. Roemmich and Sinning (1996) in their study had discovered that body fat percentage of adolescent wrestlers is $7.8 \%$. Ziyagil, Zorba, Kutlu, Tamer and Torun (1996) found that the body fat percentage of Stars Category Turkish National Wrestlers with the average age of 16.09 years is 5.99\% one years before and $6.71 \%$ one year later. In the years 1978 and 1979 average body fat percentage of free wrestlers who attended Youth World Championship was $7.9 \%$ while the percentage of Canada Free Wrestling Team had been detected as $8.2 \%$ (Carter, 1985). Mirzaei et al. (2009) reported that the mean of body fat percentage in young wrestlers (mean age, $19.8 \pm 0.9$ years) was $10.6 \%$ with $20.1 \%$ in heavyweight wrestlers and between $7.4 \%$ to $11.4 \%$ in other weight categories.

This condition approves that assumption. Buford and colleagues in the study on determining the seasonal changes in body fat, body composition and muscular performance of colleague wrestlers had observed a significant increase between body fat ratios of wrestlers for middle and last term (Buford, Smith, Obrien, Warren \& Rossi, 2008). In a research which deals with Italian wrestlers there was not found statistically significant differences concerning to BMI, body fat $\%$ and FFM for senior high level Greco-Roman and Freestyle wrestlers (Zaccagni, 2012).

In this study somatotypes of elite wrestlers did not differ by wrestling styles (free and Greco-roman styles) while it had been detected that somatotypes of wrestlers who took place in light, middle and heavy weight contests were different. Observed somatotype values showed that light, middle and heavy weight wrestlers are balanced mezomorph, endomorphic mezomorph and endomorphic mezomorph, respectively. No significant differences had been observed in free and Greco-roman styles. Average somatotype values for all the wrestlers between the 1960 and 1976 Olympics had been observed as 2.5-6.5-1.5. In addition, young wrestlers were less mezomorphic and more ectomorphic than adults (Carter \& Locio, 1986). De Garay, Levine and Carter (1974) had found that the somatotypes of the wrestlers who attended 1968 Olympics as endomezomorph. Horswill, in the study made in 1992 had detected that the somatotypes of wrestlers are balanced mesomorph (Horswill, 1992). For 1960-1976 Olympics average values for all the wrestlers found were 2.5-6.5-1.5 (Carter \& Healt, 1990). Gürses and Olgun (1979) had compared Turkish wrestlers with wrestlers who attended Montreal Olympics and evaluated Turkish wrestlers as balanced mezomorph (2.39-5.88-1.44), wrestlers attended Montreal Olympics as balanced mezomorph (2.40-6.70-1.50). Shin, (1985) in the study performed in 1985 on 19 elite wrestlers with an average age of 20.3 have detected the somatotypes of wrestlers as 2.2-6.2-1.7 and observed that they were balanced mezomorph. Carter and Lucio (1986), in 1986 had worked on 83 wrestlers with an average age of 17.8 and determined their somatotypes according to weights. Observed results showed that somatotypes of wrestlers between 52.2 and $58.9 \mathrm{~kg}$ were 1.7-4.9-3.7 ectomorphic mezomorph, somatotypes of wrestlers between 59.0 and 63.9 $\mathrm{kg}$ were 1.8-5.4-3.4 endomorphic mezomorph, somatotypes of wrestlers between 64.0 and $71.1 \mathrm{~kg}$ were 1.8-5.4-3.0 endomorphic mezomorph, somatotypes of wrestlers between 71.2 and $80.6 \mathrm{~kg}$ were 2.1-6.2-2.4 balanced mezomorph, somatotypes of wrestlers between 80.7 and $88.0 \mathrm{~kg}$ were 2.7-6.5-2.2 balanced mezomorph which are similar to the study. Carter (1985), in the study on wrestler who attended the Olympics in 1984 had detected that somatotypes of wrestlers of $60 \mathrm{~kg}$ or less were 2.1-6.4-1.6 balanced mezomorph, somatotypes of wrestlers between 60.0 and $79.9 \mathrm{~kg}$ were 2.1-6.4-1.6 balanced mezomorph, somatotypes of wrestlers between 80.0 and $99.9 \mathrm{~kg}$ were 2.6-7.0-1.2 endomorphic mezomorph and somatotypes of wrestlers of 100.0 and higher were 4.2-7.3-0.8 endomorphic mezomorph. These results are also similar to the study. Sterkowicz, Sterkowicz, and Zarów (2011) examined the somatotypes of 12 heavyweight and 11 middle-sized male greco-roman wrestlers with a mean age of 24.9 years. Heavy weight wrestlers have been found to have higher endomorphic and mesomorphic values. Noh, Kim and Kim (2015) compared 13 elite free wrestlers with 13 nonathletes somatotypes. They have put there that wrestlers have a higher mesomorphic value.

Eiin, Flyger and Wilson (2007) in the study performed on 108 athletes, 68 of whom were male, aimed to determine the somatotypes of the athletes and at the end of the study they reached the values for male athletes that were endomorph 2.7, mezomorph 5.2 and ectomorph 2.8. Among the branches shooter exhibited endomorphic mezomorph with the somatotype values of 5.9-7.5-0.7. These results are also similar to the study. Ramirez- Velez, et al. (2014) evaluated the Colombian Wrestling Team prepared for the Olympic Games $(n=21$; age, $27.9 \pm 6.7$ years $)$. As a result, they found average body fat percentages as $13.6 \%$ and somatotype average as 5.3-1.6-3.8 mesomorphic ectomorphs. The ectomorphic component was found to be higher in this study. indicating that Colombian national team wrestlers are weaker than Turkish national team wrestlers.

Increase in endomorph and mezomorph coefficients are observed in parallel to increasing weight. Making a general evaluation; somatotype distribution in the light weights, endomorph coefficient is lowest, mezomorph is dominant and ectomorph coefficient is greater than the endomorph coefficient while in the heavy weights depending on the increasing 
body weight endomorph coefficient is greater than ectomorph and less than mezomorph, meaning tends to be endomezomorph. No significant differences are observed between free and Greco-roman styles.

Analysis on physical development of wrestlers results in the conclusion that wrestlers have an specific structure especially described by improving neck muscles, chest and shoulder circumferences and upper extremities. Measurements made discovered that basic body ratios of wrestlers do not exhibit any significant differences in terms of styles and weights.

Rajabi, Doherty, Goodarzi and Hemayattalab (2008) in the study made in 2008 evaluated free and Greco-roman wrestlers as two groups whose spinal cords are located differently according to their styles, compared them with the control group and determined that thoracic khyhosis mostly occurred in free style wrestlers and at least in Greco-roman wrestlers. James and Wayne (1997) in the study performed to observe the changes in physical properties of wrestler before and after season detected that tightened arm circumference was $30.1 \mathrm{~cm}$ before the season and $31.7 \mathrm{~cm}$ after the season, forearm circumference was $26.1 \mathrm{~cm}$ before the season and $26.5 \mathrm{~cm}$ after the season, wrist circumference was $16.4 \mathrm{~cm}$ before the season and $16.6 \mathrm{~cm}$ after the season, calf circumference was $34.5 \mathrm{~cm}$ before the season and $34.8 \mathrm{~cm}$ after the season, chest circumference was $90.0 \mathrm{~cm}$ before the season and $92.5 \mathrm{~cm}$ after the season and waist circumference was $71.9 \mathrm{~cm}$ before the season and $74.7 \mathrm{~cm}$ after the season and the observed data are similar to present study's values.

Keogh, Hume, Pearson and Mellow (2007) in their study aimed to determine anthropometric differences between powerlifters by classifying them according to their weights, found the somatotypes of subjects as 3.2-7.5-1.1 for light weights, 3.1-8.0-0.7 for middle weights and 6.3-10.7-0.1 for heavy weights. These numbers show that their somatotypes were balanced mezomorph. Neck circumference (L:37.1 cm, M:41.5 cm, H:47.4 cm), upper arm in flexion (L:37.0 cm, M:40.0 cm, H:46.4 cm), chest circumference (L:101.3 cm, M:109.7 cm, H:126.0 cm), waist circumference (L:76.6 cm, M:90.5 cm, H:109.6 cm), calf circumference (L:36.4 cm, M:38.8 cm, H:45.0 cm), biacromial breadth (L:40.3 cm, M:42.0 cm, H:44.3 cm), humerus breadth $(\mathrm{L}: 7.0 \mathrm{~cm}, \mathrm{M}: 7.8 \mathrm{~cm}, \mathrm{H}: 8.0 \mathrm{~cm})$, femur breadth $(\mathrm{L}: 9.7 \mathrm{~cm}, \mathrm{M}: 10.3 \mathrm{~cm}$, $\mathrm{H}: 11.3 \mathrm{~cm}$ ) and the results are similar to those of present study.

Vila et al. (2009) in the study on water polo players having an average age of 12.77 years found average anthropometric parameters of the players as follows: Biacromial breadth $44.58 \mathrm{~cm}$, humerus breadth $7.26 \mathrm{~cm}$, femur breadth $10.18 \mathrm{~cm}$, upper arm circumference in flexion $37.31 \mathrm{~cm}$, chest circumference $106.10 \mathrm{~cm}$, waist circumference $86.46 \mathrm{~cm}$, calf circumference $37.69 \mathrm{~cm}$ and also the somatotype values; endomorph 2.91, mezomorph 5.46 ectomorph 2.16 , meaning balanced mezomorph.

The results of present study concerning elite wrestlers show that body compositions of those who deals with wrestling sport at elite level do not differ between styles (free and Greco-roman). As the styles do not have diversifying effect on the wrestlers who are involved in similar training, feeding and contest programs as of childhood, on the other hand weights depend on the somatotype differentiation within the scope of factors such as length, body weight, bust and arm length are affective for diversifying.

\section{Conclusion}

The results of this study to address the elite wrestlers shows that the elite level of sport wrestling exercise of those styles, there is no difference between body compositions of Free and Greco-Roman wrestlers Since childhood, like training, nutrition and competition, including programs for the wrestler style parser of an effect observed; contrast of height, body weight, bust and arms-length elements, such as somatotypes under different weights based on the decomposition of the source that can be seen.

The present study evaluated anthropometric and physical performance variables that might affect wrestling performance. These data provided a profile of elite Turkish wrestlers and enabled comparison with international data. These results provided a profile of elite wrestlers that could be used as training targets for developing athletes. The results may also provide information for training and tactical planning.

While these anthropometric and somatotype variables alone do not predict success in a sport where strategy and technique are also essential elements, they do provide useful reference values to determine training priorities for the development of the elite wrestler and in talent identification.

\section{References}

Bompa, T. O., \& Haff, G. G. (2009). Periodization: Theory and Methodology of Training. USA: Human Kinetics.

Buford, T. W., Smith, D. B., Obrien, M. S., Warren, A. J., \& Rossi, S. J. (2008). Seasonal changes of body mass, body composition and muscular performance in collegiate wrestlers. International Journal of Sports Physiology and Performance, 3(2), 176-184. https://doi.org/10.1123/ijspp.3.2.176. 
Bujak, Z., Dariusz, G. D., Hubner-Wozniak, E., \& Sergejs, S. S. (2016). Anthropometric profile and anaerobic capacity of martial arts and combat sports athletes. IDO MOVEMENT FOR CULTURE. Journal of Martial Arts Anthropology, 16(2), 55-59. https://doi.org/10.14589/ido.16.2.7

Camic, C. L., Housh, T. J., Mielke, M., Hendrix, C. R., Zuniga, J. M., Johnson, G. O., Housh, D. J., \& Schmidt, R. J. (2009). Age-related patterns of anthropometric characteristics in young wrestlers. Medicine and Science in Sports and Exercise, 41(5), 1014-1019. https://doi.org/10.1249/MSS.0b013e3181914745

Carter, J. E. L. (1985). Somatotypes of olympic athletes from 1948 to 1976. in physical structure of olympic athletes. Part II. Kinanthropometry of olympic athletes. Basel, Karger.

Carter, J. E. L., \& Locio, F. D. (1986). Body size, skinfold and somatotypes of high scholl and olympic wrestlers. In perspectives in kinanthropometry. Illinois: Human Kinetics.

Carter, L. J. E., \& Heath, B. H. (1990). Somatotyping-development and aplications. New York: Cambridge University Press.

Charzewski, J., Głaz, A., \& Kuźmicki, S. (1991). Somatotype characteristics of elite European wrestlers. Biology of Sport, 8(4), 213-221. Retrieved from

https://books.google.com.tr/books?id=MPsOVAigne4C\&printsec=frontcover\&hl=tr\&source=gbs_ge_summary_r $\& \mathrm{cad}=0 \# \mathrm{v}=$ onepage $\& \mathrm{q} \& \mathrm{f}=$ false

Clark, R., Robert, A., \& Jude, C. (2002). Cross-validation of the NCAA method to predict body fat for minimum weight in collegiate wrestlers. Clinical Journal of Sport Medicine. 12(5), 285-290. Retrieved from https://insights.ovid.com/pubmed?pmid=12394200

De Garay, A. L., Levine, L., \& Carter, J. E. L. (1974). Genetic and anthropological studies of olympic athletes. New York: Academic Press.

Eiin, V. J., Flyger, N., \& Wilson, N. (2007). Somatotypes of young malaysian track and field athletes. Asian Journal of Exercise \& Sports Science, 1(4), 1-7. Retrieved from https://www.researchgate.net/profile/Jyh_Eiin_Wong/publication/269519517_Somatotypes_of_young_Malaysian_ track_and_field_athletes/links/54ab4ade0cf2bce6aa1d860c/Somatotypes-of-young-Malaysian-track-and-field-athle tes.pdf

Eston, R., \& Reilly, T. (1996). Kinanthropometry and exercise physiology laboratory manual. London: An Imprint of Chapman \& Hall.

Fox, E. L., Bowers, R. W., \& Foss, M. L. (1988). The physiological basis of physical education and athletics. Philadelphia: Saunders College Publishing.

Green, S., Salkind, N. J., \& Akey, T. (2000). Using SPSS for windows: analyzing and understanding data. New Jersey: Prentice Hall.

Gürses, Ç., \& Olgun, P. (1979). Sportif yetenek araştırma metodu: Türkiye uygulaması. İstanbul: Türk Spor Vakfı Yayınları.

Guyton, A. C., \& Hall, J. E. (2001). Textbook of medical physiology. Philadelphia: A Harcount Health Sciences Companys.

Heyward, V. H., \& Wagner, D. R. (2004). Applied body composition assessment. USA: Human Kinetics.

Horswill, C. A. (1992). Applied Physiology of Amateur Wrestling. Sports Medicine. 14(2), 114-143. Retrieved from https://www.researchgate.net/publication/21646948

Jagiełło, W., \& Kruszewski, A. (2009). Morphological diversification of competitors training Greko-Roman style of wrestling. Archives of Budo, 1(5), 147-153. Retrieved from files.4medicine.pl/download.php?cfs_id=1173

James, N., \& Wayne, E. (1997). Weight loss and wrestling training: effects on nutrition, growth, maturation, body composition, and strength. Journal of Applied Physiology, 6(82), 1751-1759. https://doi.org/10.1152/jappl.1997.82.6.1751

Karl, K. (Harputoğlu, H. Trans.) (2001). Sporda yetenek arama, seçme ve yönlendirme. Ankara: Bağırgan Yayınevi.

Kazemi, M., Waalen, J., Morgan, C., \& White, A. R. (2006). A profile of olympic taekwondo competitors. Journal of Sports Science and Medicine, 1(5), 114-121. Retrieved from https://www.ncbi.nlm.nih.gov/pmc/articles/PMC3863920/pdf/jssm-05-CSSI1-114.pdf

Keogh, J. W. L., Hume, P. A., Pearson, S. N., \& Mellow, P. (2007). Anthropometric dimensions of male powerlifters of varying body mass. Journal of Sports Sciences, 25(12), 1365-1376. https://doi.org/10.1080/02640410601059630 
Lohman, T. G., Roche, A. F., \& Martorell, R. (1988). Antropometric standardization reference manual. ABD: Champaign, Human Kinetics Books.

Mirzaei, B., Curby, D. G., Rahmani-Nia, F., \& Moghadasi, M. (2009). Physiological profile of elite Iranian junior freestyle wrestlers. The Journal of Strength \& Conditioning Research, 23(8), 2339-2344. https://doi:10.1519/JSC.0b013e3181bb7350

Nilsson, J., Csergö, S., Gullstrand, L., Tveit, P., \& Refsnes, P. E. (2002). Work-time profile, blood lactate concentration and rating of perceived exertion in the 1998 Greco-Roman Wrestling World Championship. Journal of Sports Sciences, 20(11), 939-945. https://doi.org/10.1080/026404102320761822

Noh, J. W., Kim, J. H., \& Kim, J. (2015) Somatotype analysis of freestyle wrestlers compared with nonathletes for health science research. Toxicology and Environmental Health Sciences. 6(4), 244-250. Retrieved from https://page-one.live.cf.public.springer.com/pdf/preview/10.1007/s13530-014-0212-y

Rajabi, R., Doherty, P., Goodarzi, M., \& Hemayattalab, R. (2008). Comparison of thoracic kyphosis in two groups of elite Greco-Roman and freestyle wrestlers and a group of non-athletic participants. British Journal of Sports Medicine, 42(3) 229-232. http://dx.doi.org/10.1136/bjsm.2006.033639

Ramirez-Velez, R., Argothyd, R., Meneses-Echavez, J. F., Beatriz Sanchez-Puccini, M., Lopez-Alban, C. A., \& Cohen, D. D. (2014). Anthropometric characteristics and physical performance of Colombian elite male wrestlers. Asian Journal of Sports Medicine. 5(4), e23810. Retrieved from https://www.ncbi.nlm.nih.gov/pmc/articles/PMC4335472/pdf/asjsm-05-23810.pdf

Roemmich, J. N., \& Sinning, W. E. (1996). Sports-seasonal changes in body composition, growth, power and strength of adolescent wrestlers. International Journal of Sports Medicine, 17(2), 92-99. https://doi.org/10.1055/s-2007-972814

Shin, S. G. (1985). A research on athlete's somatotype, body composition and maximum oxygen uptake ability. Ms Thesis. Dong-A University, Pusan, Korea.

Sterkowicz-Przybycień, K. L., Sterkowicz, S., \& Zarów, R. T. (2011). Somatotype, body composition and proportionality in polish top greco-roman wrestlers. Journal of Human Kinetics, 28, 141-154. https://doi:10.2478/v10078-011-0031-z. epub 2011 jul 4.

Vila, H., Ferragut, C., Argudo, F. M., Abraldes, J. A., Rodríguez, N., \& Alacid, F. (2009). Relationship between anthropometric parameters and throwing velucity in water polo players. Journal of Human Sport \& Exercise, 4(1), 57-68. Retrieved from https://rua.ua.es/dspace/bitstream/10045/8970/1/E_JHSE_4_1_7.pdf

Weiner, J. S., \& Lourie, J. A. (1981). Practical human biology. London: Academic Press,

Zaccagni, L. (2012). Anthropometric characteristics and body composition of Italian national wrestlers. European Journal of Sport Science, 12(2), 145-151. https://doi.org/10.1080/17461391.2010.545838

Ziyagil, M. A., Zorba, E., Kutlu, M., Tamer, K., \& Torun, K. (1996). Bir yıllık antrenmanın yıldızlar kategorisindeki serbest stil türk milli takım güreşçilerinin vücut kompozisyonu ve fizyolojik özellikleri üzerine etkisi. Gazi Beden Ĕ̈itimi ve Spor Bilimleri Dergisi. 1(4), 9-16. Retrieved from http://www.dergipark.gov.tr/download/article-file/289157

Zorba, E. (2005). Vücut yapısı ölçüm yöntemleri ve şişmanlıkla başa çıkma. İstanbul: Morpa Kültür Yayınları.

\section{Copyrights}

Copyright for this article is retained by the author(s), with first publication rights granted to the journal.

This is an open-access article distributed under the terms and conditions of the Creative Commons Attribution license which permits unrestricted use, distribution, and reproduction in any medium, provided the original work is properly cited. 